\title{
A COMPARATIVE STUDY ON THE OUTCOMES OF VARIOUS MODALITIES OF SURGICAL MANAGEMENT OF BENIGN PROSTATIC HYPERPLASIA
}

\author{
Ravikumar R. Jadhav1, Priyadarshini C. A2 , Aswathy Chandran ${ }^{3}$
}

${ }^{1}$ Associate Professor, Department of General Surgery, Karnataka Institute of Medical Sciences, Hubballi. 2Junior Resident, Department of General Surgery, Karnataka Institute of Medical Sciences, Hubballi. 3Junior Resident, Department of General Surgery, Karnataka Institute of Medical Sciences, Hubballi.

\section{ABSTRACT}

\section{BACKGROUND}

Benign prostatic hyperplasia is one of the most common ailments affecting elderly men. The lower urinary tract symptoms caused by it are distressing and cause significant morbidity. Most symptoms are manifested as derangement in urination due to the close anatomical relation between the bladder and the prostate.

The present study was undertaken to study the surgical management of benign prostatic hyperplasia with emphasis on transurethral resection of prostate, transurethral vapourisation and open prostatectomy.

\section{MATERIALS AND METHODS}

The study was a prospective hospital-based time-bound observational study conducted between December 2013 and May 2015 at a Medical College Hospital.

\section{RESULTS}

The maximum incidence of the disease was in the age group of 61 - 70 years. The next commonest mode of presentation was acute retention of urine followed by a weak stream. The average operating time for open prostatectomy was significantly higher. Urinary incontinence following minimally invasive procedures like TURP and TUVP was more common than following open prostatectomy. The average improvement in the symptoms of the patients who underwent TURP and TUVP for BPH at 3 months are similar and less when compared to open prostatectomy.

\section{CONCLUSION}

TURP is the gold standard in the management of benign prostatic hyperplasia with earlier recovery and lesser postoperative complications.

\section{KEYWORDS}

International Prostate Symptom Score, Benign Prostatic Hyperplasia, Transurethral Resection of Prostate.

HOW TO CITE THIS ARTICLE: Jadhav RR, Priyadarshini CA, Chandran A. A comparative study on the outcomes of various modalities of surgical management of benign prostatic hyperplasia. J. Evolution Med. Dent. Sci. 2017;6(90):6381-6385, DOI: $10.14260 /$ jemds/2017/1387

\section{BACKGROUND}

Benign prostatic hyperplasia (BPH) is one of the common ailments affecting elderly men.(1) The lower urinary tract symptoms (LUTS) caused due to it are depressing and cause significant morbidity. These include obstructive or voiding symptoms and irritative or storage symptoms. Voiding symptoms include weak urinary stream, hesitancy, intermittency, dribbling and incomplete emptying. Storage symptoms include frequency, nocturia, urgency, urge incontinence and dysuria. The prevalence of LUTS in the male population increases with age and has been estimated to be $20 \%-25 \%$ for the middle-aged men and $40 \%-70 \%$ for men aged 70 years and above.(1,2) In 1992, The American Urological Association (AUA) published the Symptom Scoring Index,

'Financial or Other Competing Interest': None.

Submission 17-07-2017, Peer Review 07-11-2017,

Acceptance 14-11-2017, Published 20-11-2017.

Corresponding Author:

Dr. Aswathy Chandran,

Room No. 49,

Chetana Hostel

KIMS Campus,

Hubli.

E-mail: aswathydot@gmail.com

DOI: $10.14260 /$ jemds $/ 2017 / 1387$

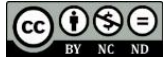

which was adopted by the World Health Organisation in 1993 as the International Prostate Symptom Score (IPSS). It consists of seven questions referring to LUTS as in AUA symptom index with an additional question referring to quality of life.(3)

The treatment of BPH has undergone a long development in the past two decades. Surgical modalities have undergone a revolutionary change with minimally invasive techniques, such as transurethral resection of prostate (TURP) becoming the mainstay of operative management with open surgery being reserved for larger glands associated with urethral stricture. Transurethral electrovaporisation of the prostate (TUVP) is a modification of the existing transurethral technology and is the most recent alternative to TURP, which uses a grooved roller ball electrode and pure cutting current to scrape out the prostatic bed and claimed advantages of little or no bleeding, fluid absorption or electrolyte imbalance.(3,4) Various modifications of TURP like bipolar/ saline TURP and holmium laser enucleation of prostate have evolved and are shown to have favourable long-term outcomes.

We planned a study to review the surgical treatment options currently available for $\mathrm{BPH}$, the efficacy of the standard transurethral resection of prostate, transurethral vaporisation and open prostatectomy and study the 
outcomes, morbidity and complications associated with the procedures.

\section{MATERIALS AND METHODS}

The study was a prospective observational study conducted between December 2013 and May 2015 at a Medical College Hospital. All patients with benign prostatic hyperplasia admitted and operated by either transurethral resection of prostate, transurethral vaporisation or open prostatectomy were chosen for the study. The primary outcome was to study the efficacy and safety of the various modalities of surgical management in patients with benign prostatic hyperplasia. We chose a sample size of 40 patients. Patients with clinical features of bladder outlet obstruction due to BPH, those with moderate-to-severe symptoms with failed medical management, renal insufficiency and hydronephrosis due to $\mathrm{BPH}$, patients with recurrent urinary retention, recurrent haematuria of prostatic origin, patients with vesical calculus and patients with urinary tract infection were included in the study. Patients who were medically unfit for surgery, those who declined surgery and request medical management, patients with bladder outlet obstruction (BOO) due to causes other than BPH and patients with BPH responding well to medical line of management were excluded from the study. The results were analysed using appropriate statistical tests like analysis of variance (ANOVA) to find the significance of study parameters between three or more groups of patients and Chi-square/ Fisher Exact test to find the significance of study parameters on categorical scale between two or more groups. The data analysis was done using SPSS V24 (IBM) software. $\mathrm{P}$ value of less than 0.05 was considered as significant.

\section{RESULTS}

Our study includes patients between 50 and 85 years; the youngest patient being 50 years and the oldest being 84 years old. The maximum incidence of the disease was in the age group of 61 - 70 years (50\%).

The patients presented with multiple symptoms. A majority of them had frequency of micturition, which was present in 35 out of 40 patients $(87.5 \%)$. The next commonest mode of presentation was acute retention of urine followed by a weak stream. There was urgency in 25 cases, nocturia in 22, incomplete evacuation in 20 , burning micturition in 16 and haematuria in 3 cases.

In the 40 patients studied, $14(35 \%)$ had comorbid conditions in the form of hypertension, diabetes mellitus or chronic obstructive pulmonary disease (COPD); 7 patients had hypertension, 4 had diabetes mellitus and 2 were known to have COPD.

Among the 40 patients studied, a majority of them had severe International prostate symptom score IPSS 27 $(67.5 \%)$ and 13 (32.5\%) had moderate IPSS (Figure 1), 10 patients had Grade 1 prostatomegaly, 22 had Grade 2 and 8 had Grade 3 prostatomegaly.

Urine examination showed pus cells in 19 cases (47.5\%) and epithelial cells in 6 cases $(15 \%)$ and haematuria in 1 case (2.5\%). Majority of the patients showed urea within normal limits (77.5\%); 9 patients showed urea above $40 \mathrm{mg} / \mathrm{dL}$. Among 40 patients, 36 (90\%) had serum creatinine within normal limits and 4 had serum creatinine values above 1.5 $\mathrm{mg} / \mathrm{dL} ; 28$ (22\%) patients had prostate volume between $31 \mathrm{~g}$ and $50 \mathrm{~g}, 8(20 \%)$ patients had prostate volume between $51 \mathrm{~g}$ - $75 \mathrm{~g}$ and $10(25 \%)$ of the patients had prostate volume above $75 \mathrm{~g}$. A majority of patients in our study (70\%) had significant post-void residual volume of $>50 \mathrm{~mL}$. However, post-void residual volume could not be assessed in 10 patients, as these patients presented to emergency room with acute retention of urine and were catheterised during ultrasonography and were subsequently operated.

The indications for surgery in our study cases were recurrent urinary retention, recurrent urinary tract infection, failed medical management, azotaemia, recurrent haematuria of prostatic origin and vesical calculus.

Out of the 40 patients studied 20 (50\%) underwent TURP, 10 (25\%) underwent TUVP and 10 underwent open prostatectomy (Figure 2).

The average operating time for TURP in our study cases was 59 minutes as compared to TUVP which was 50 minutes. The average operating time for open prostatectomy was significantly higher, which was 97 minutes with a range of 85 - 110 minutes $(\mathrm{p}<0.001)$.

20 patients who underwent TURP had an average duration of catheterisation of 3.4 days with a range of $2-4$ days and 10 patients who underwent TUVP had an average duration of catheterisation of 2.8 days, whereas the average duration of catheterisation following open prostatectomy was significantly higher viz. 7.1 days (range of 6 - 8 days).

A fall in haematocrit is indicative of intraoperative blood loss. In our study, the average fall in haematocrit following TURP and TUVP was comparable with 6.6 and 5.18 days respectively, whereas following open prostatectomy was 18.84 days which was significantly higher than TURP and TUVP.

Among 20 patients who underwent TURP, 2 patients developed urinary incontinence following surgery. One patient who underwent TUVP and one who underwent open prostatectomy developed urinary incontinence. Urinary incontinence following minimally invasive procedures like TURP and TUVP was thus more common than following open prostatectomy.

The average number of days of postoperative hospital stay for TURP and TUVP was comparable namely 5.55 days and 4.2 days respectively, which was significantly lower than that of open prostatectomy which was 9.9 days.

The average improvement in pre- and postoperative peak flow rate on uroflowmetry in patients who underwent open prostatectomy was $31 \%$ as compared to an average of $46.7 \%$ improvement in patients who underwent minimally invasive techniques like TURP and TUVP.

Among the 40 patients operated, the average improvement in IPSS at three months was $46.5 \%$ and at 1 year was $65.73 \%$. The average improvement in the symptoms of the patients as suggested by IPSS score in patients who underwent TURP for BPH at 3 months was $42.3 \%$, which was comparable to TUVP which showed $44.1 \%$ improvement in IPSS. However, the average improvement in IPSS at 1 year following open prostatectomy was $67.9 \%$, which was comparable to improvement in IPSS at one year following TURP and TUVP which was $67.7 \%$ and $64.7 \%$ respectively with no statistically significant difference (Table 1).

In our study two patients developed late complications, one patient following TURP and one patient following open 
prostatectomy developed bladder neck contracture which was managed with bladder neck incisions.

\begin{tabular}{|c|c|c|c|}
\hline Parameter & TURP & TUVP & $\begin{array}{c}\text { Open } \\
\text { Prostatectomy }\end{array}$ \\
\hline $\begin{array}{c}\text { Average duration } \\
\text { of surgery }\end{array}$ & $\begin{array}{c}59 \text { mins } \\
\text { (SD- } 6.48 \\
\text { mins) }\end{array}$ & $\begin{array}{c}50 \text { mins } \\
\text { (SD- } 7.4 \\
\text { mins) }\end{array}$ & $\begin{array}{c}97 \text { mins } \\
\text { (SD- } 5.6 \text { mins })\end{array}$ \\
\hline $\begin{array}{c}\text { Average duration } \\
\text { of postoperative } \\
\text { catheterisation }\end{array}$ & $\begin{array}{c}3.9 \text { days } \\
\text { (SD- } 0.33 \\
\text { days) }\end{array}$ & $\begin{array}{c}2.8 \text { days } \\
\text { (SD- } 0.56 \\
\text { days }\end{array}$ & $\begin{array}{c}7.1 \text { days } \\
\text { (SD- } 1.33 \text { days) }\end{array}$ \\
\hline $\begin{array}{c}\text { Duration of } \\
\text { hospital stay post- } \\
\text { operatively }\end{array}$ & $\begin{array}{c}5.5 \text { days } \\
(1.33 \text { days) }\end{array}$ & $\begin{array}{c}4.2 \text { days } \\
(0.56 \text { days) }\end{array}$ & $\begin{array}{c}9.9 \text { days } \\
(2.33 \text { days })\end{array}$ \\
\hline $\begin{array}{c}\text { Improvement in } \\
\text { IPSS one year after } \\
\text { surgery }\end{array}$ & $67.7 \%$ & $64.7 \%$ & $67.9 \%$ \\
\hline $\begin{array}{c}\text { Table 1. Comparison of Outcomes of TURP, TUVP and Open } \\
\text { Prostatectomy }\end{array}$ \\
\hline
\end{tabular}

\section{SEVERITY OF IPSS AT PRESENTATION}

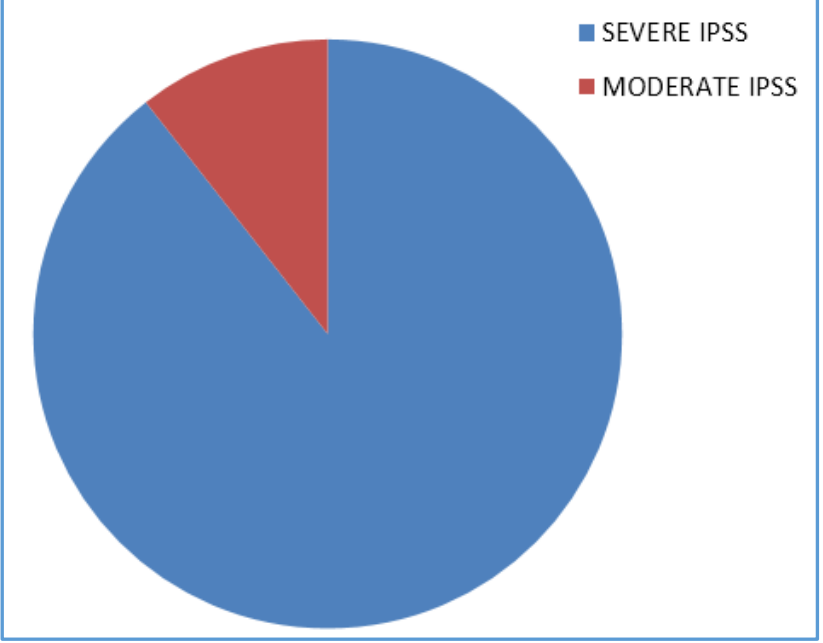

Figure 1. Pie Diagram showing Severity of IPSS at Presentation

\section{VARIOUS MODALITIES OF TREATMENT UNDERGONE BY THE PATIENTS}

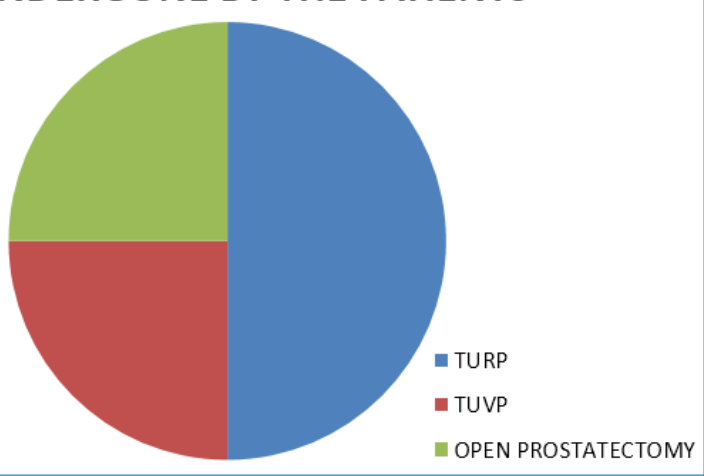

Figure 2. Pie Diagram showing the Various Modalities of Treatment undergone by the Patients

\section{DISCUSSION}

In our study, the average group in which there was maximum incidence of benign prostatic hyperplasia was in the range between 61 - 70 years; the incidence was 20 out of 40 patients in our study, that is $50 \%$ of the patients. Age specific incidence in our study can be compared with the study of Glenn RJ et al.(5) The age specific incidence in our study is comparable to the Glynn study in the 6th decade, but thereafter the incidence in our study has decreased. This may be due to lesser patients in the older age group managed surgically and maybe due to low life expectancy.

Majority of our study patients (87.5\%) had frequency of micturition followed by acute retention of urine (29\%), which were the symptoms at presentation. Ibrahim Ahmed Gadam et al studied 253 patients with BPH who underwent surgery. Among these 229 (90.5\%) patients had frequency, which was the most common symptom of presentation which was similar to our study (87.5\%).(6,7) $37.5 \%$ of our patients had co-morbidities in the form of hypertension, diabetes and obstructive pulmonary disease. The average IPSS scores at presentation in TURP, TUVP and open prostatectomy groups were 25.35, 20.1 and 27.8 respectively. Majority of the patients had severe symptoms $(67.5 \%)$ according to IPSS and the rest of the patients had moderate symptoms. 55\% of the patients in our study had Grade 2 prostatomegaly followed by $25 \%$ with Grade 1 prostatomegaly and $20 \%$ patients with Grade 3 prostatomegaly on digital rectal examination. A large number of patients showed associated urinary tract infection. Majority of the patients had prostate volume between 31 and 50 cc. The average prostate volume in patients who underwent TURP and TUVP were $45.9 \mathrm{cc}$ and $37.1 \mathrm{cc}$ respectively, whereas the average prostate volume in patients who underwent open prostatectomy was 93.9 cc. The most common indication for surgery was recurrent urinary retention followed by severe symptoms not responding to medical management. The mean operating time for TURP and TUVP were significantly lower compared to open prostatectomy. Fall in haematocrit was higher in open prostatectomy group than compared to TURP and TUVP. The improvement in IPSS at 3 months following surgery was more after open prostatectomy than compared to TURP and TUVP, probably because of more severe symptoms at presentation in the open group which could have caused more relief of symptoms after surgery; however, all three procedures showed similar improvement in IPSS at 1 year following surgery. The outcomes of TURP and TUVP in terms of operating time, duration of catheterisation, fall in haematocrit, hospital stay and postoperative complications were comparable in our study.

Our study results thus revealed that TURP was associated with shorter operating time, lesser duration of postoperative catheterisation, lesser fall in haematocrit and shorter postoperative stay compared to open prostatectomy; however, open prostatectomy was associated with a higher improvement in IPSS after three months compared to TURP and TUVP, but the improvement in symptoms after one year was comparable in all the three groups. In a study conducted by Suhani et al on the outcome of surgery for 60 patients of $\mathrm{BPH}, 50$ underwent TURP and 10 underwent open prostatectomy. According to the study the average IPSS at presentation for TURP group was $29.7 \%$ and for open prostatectomy was 28.75 , which are comparable to our study $25.35 \%$ and $28.75 \%$ respectively. 
Bladder neck contracture (BNC) is a well-described complication that may occur following the surgical treatment of benign and malignant prostate conditions. $(8,9)$ Prostatectomy patients are likely to develop BNC due to technical factors at the level of the vesicourethral anastomosis (i.e. urine leak, haematoma, undue tension).(10) Risk factors for BNC development after prostatectomy include a history of diabetes mellitus, coronary artery disease, obesity, surgeon experience, surgical technique and certain postoperative complications (haemorrhage, prolonged urine leak, anastomotic disruption)(11); nevertheless, in our study one patient developed bladder neck contracture after open prostatectomy. This patient had diabetes mellitus and hypertension as risk factors. BNC is a well-recognised complication following robot-assisted radical prostatectomy (RARP) for treatment of localised prostate cancer with a reported incidence of up to $1.4 \% .(12,13)$ Our study did not include procedures like RARP, since they are not done in our institute.

A study of the clinical and urodynamic outcome of men with lower urinary tract symptoms with and without previous urodynamic evaluation submitted to transurethral resection of the prostate suggested that the previous urodynamic study is not the only factor related to the success of surgical outcome, and therefore the symptomatology and uroflowmetry associated would be enough during the preoperative routine studies for BPH patients(13); nevertheless, in our study the average improvement in preand postoperative peak flow rate on uroflowmetry in patients who underwent open prostatectomy was $31 \%$ as compared to an average of $46.7 \%$ improvement in patients who underwent minimally invasive techniques like TURP and TUVP.

Most men will have a watertight anastomosis on postoperative day (POD) 3 or 4 after radical resection of prostate. Early catheter removal does not have a negative impact on continence or the rate of anastomotic strictures. (14) Because of the high incidence of acute urinary retention requiring replacement of the urinary catheter and the potential for disruption of the anastomosis or bladder neck reconstruction, Patel $\mathrm{R}$ recommend delaying catheter removal until POD 7 or later.(15) In our study, patients who underwent TURP had an average duration of postoperative catheterisation of 3.4 days with a range of 2 - 4 days and patients who underwent TUVP had an average duration of 2.8 days, whereas the average duration of catheterisation following open prostatectomy was significantly higher at 7.1 days (range of 6 - 8 days).

In a study done on patients undergoing TURP in a district hospital, older age of the patient, larger resections and late removal of suprapubic catheters were statistically significant in prolonging LOS (Length of Stay) ( $\mathrm{P}<0.001)$. General anaesthesia was associated with longer stay than regional anaesthesia, but the difference was not statistically significant. In our study, the average postoperative hospital stay for TURP was 5.5 days, 4.2 days for TUVP and 9.9 days for open prostatectomy and all these cases were done under regional anaesthesia.

Our study has some limitations. We included a limited number of patients undergoing surgical management for BPH and also a limited followup period. We suggest that further studies with a larger number of patients can be conducted in this direction.

\section{CONCLUSION}

We conclude from our study that TURP is the gold standard in the management of benign prostatic hyperplasia with earlier recovery and lesser postoperative complications.

\section{REFERENCES}

[1] Netto NR, de Lima ML, Netto MR, et al. Evaluation of patients with bladder outlet obstruction and mild international prostate symptom score followed up by watchful waiting. Urology 1999;53(2):314-6.

[2] Roehrborn CG. Benign prostatic hyperplasia: an overview. Rev Urol 2005;7(Suppl 9):S3-S14.

[3] Berges R, Oelke M. Age-stratified normal values for prostate volume, PSA, maximum urinary flow rate, IPSS, and other LUTS/BPH indicators in the German male community-dwelling population aged 50 years or older. World Journal of Urology 2011;29(2):171-8.

[4] Kaplan SA. Update on the American urological association guidelines for the treatment of benign prostatic hyperplasia. Rev Urol 2006;8(4):S10-S17.

[5] Wasson JH, Reda DJ, Bruskewitz RC, et al. A comparison of transurethral surgery with watchful waiting for moderate symptoms of benign prostatic hyperplasia. The Veterans Affairs Cooperative Study Group on Transurethral Resection of the Prostate. New England Journal of Medicine 1995;332(2):75-9.

[6] Fitzpatrick, John M, Ambirani W. Therapeutic strategies in managing benign prostatic hyperplasia progression. European Urology Suppliments 2006;20(50):997-1003.

[7] Glynn RJ, Campion EW, Bouchard GR, et al. The development of BPH among the volunteers in normative ageing study. Am J Epidemiology 1985;121(1):78-90.

[8] Gupta N, Sivaramakrishna, Kumar R, et al. Comparison of standard transurethral resection, transurethral vapour resection and holmium laser enucleation of prostate for managing benign prostatic hyperplasia of $>40$ g. BJU International 2006;97(1):85-9.

[9] Suhani S, Gupta S, Gupta A, et al. Outcome of surgery in benign prostatic hyperplasia-Is it predictable?-is it predictable? Journal of Clinical and Diagnostic Research 2013;7(12):2859-62.

[10] Tubaro A, d Nunzio C. The current role of open surgery in BPH. European Association of Urology 2006;4:191201.

[11] Hammadeh MY, Philp T. Transurethral electrovapourisation of the prostate (TUVP) is effective, safe and durable. Prostate Cancer and Prostatic Diseases 2003;6(2):121-6.

[12] Ko DSC, Fenster HN, Chambers K, et al. The correlation of multichannel urodynamic pressure-flow studies and American Urological Association symptom index in the evaluation of benign prostatic hyperplasia. J Urol 1995;154(2 Pt 1):396-8. 
[13] Abrams P. In support of pressure-flow studies for evaluating men with lower urinary tract symptoms. Urology 1994;44(2):153-5.

[14] McConnell JD, Barry MJ, Bruskewitz RC, et al. Benign prostatic hyperplasia: diagnosis and treatment. Clinical Practice Guidelines, number 8. AHCPR Publication N. 94-0582. Rockville, Maryland: Agency for Healthcare Policy and Research, Public Health
Service, U.S. Department of Health and Human Services Clin Pract Guidel Quick Ref Guide Clin 1994;(8):1-17.

[15] Patel R, Lepor H. Removal of urinary catheter on postoperative day 3 or 4 after radical retropubic prostatectomy Urology 2003;61(1):156-60. 